\title{
Neglected Stress Fracture of Navicular Bone: A Case Report and Literature Review
}

\author{
${ }^{1}$ Sundararajan Silvampatti, ${ }^{2}$ AR Pradeep, ${ }^{3} \mathrm{~S}$ Rajasekaran
}

\begin{abstract}
Navicular fractures are the most common stress fractures of tarsal bones, with calcaneum fractures accounting for almost all of the remainder. Diagnosis is commonly delayed and these fractures carry on with a risk of displacement and nonunion, thus affecting the outcome.

A 17-year-old university level female athlete presented with pain along the anteromedial aspect of her foot suffering since one- and half-year without a history of specific trauma. On evaluation, she was found to have stress fracture of navicular bone which was neglected and has gone for nonunion.

Satisfactory outcome was achieved by open reduction and internal fixation with cancellous screw and iliac crest strut grafting followed by appropriate rehabilitation.
\end{abstract}

Keywords: Stress fracture, Navicular, Strut graft, Cancellous screw.

How to cite this article: Silvampatti S, Pradeep AR, RajasekaranS. Neglected Stress Fracture of Navicular Bone: A Case Report and Literature Review. J Foot Ankle Surg (Asia-Pacific) 2015;2(1): 38-40.

\section{Source of support: Nil}

Conflict of interest: None

\section{INTRODUCTION}

Navicular fractures are the most common stress fractures of tarsal bones, with calcaneum fractures accounting for almost all of the remainder. Jumping and sprinting sports, such as athletics or basketball are often associated with such fractures. ${ }^{1}$ Diagnosis is commonly delayed and these fractures carry on with a risk of displacement and nonunion, thus affecting the outcome.

We report a case of a one- and half-year-old neglected navicular stress fracture in a young athlete treated with iliac crest strut graft and cancellous screw fixation.

\section{CASE REPORT}

A 17-year-old university level female athlete presented with pain along the anteromedial aspect of her foot

\footnotetext{
${ }^{1}$ Consultant, ${ }^{2}$ Fellow, ${ }^{3}$ Chairman

${ }^{1-3}$ Department of Orthopedics, Ganga Hospital, Coimbatore Tamil Nadu, India

Corresponding Author: Sundararajan Silvampatti, Consultant Department of Orthopedics, Ganga Hospital, Coimbatore Tamil Nadu, India, Phone: 04222485000, e-mail: sundarbone70 @hotmail.com
}

suffering since one- and half-year without a history of specific trauma. Since then, the disability refrained her from participating in activities like sports, along with walking, climbing stairs and squatting.

Her condition was not diagnosed initially. She continued to have foot pain, which affected her participation in sports, she was referred for a sports medicine consultation.

On examination, focal tenderness over the dorsal aspect of the medial midfoot and anteromedial aspect of ankle was found. Weight-bearing arch height was normal. The talocrural joint had normal plantar flexion, inversion and eversion. Dorsiflexion was 0 to $20^{\circ}$ and plantar flexion was 0 to $40^{\circ}$. Plain radiograph (Fig. 1), computed tomography (CT) scan and magnetic resonance imaging (MRI) scan (Fig. 2) were done showing nonunion of stress fracture of navicular.

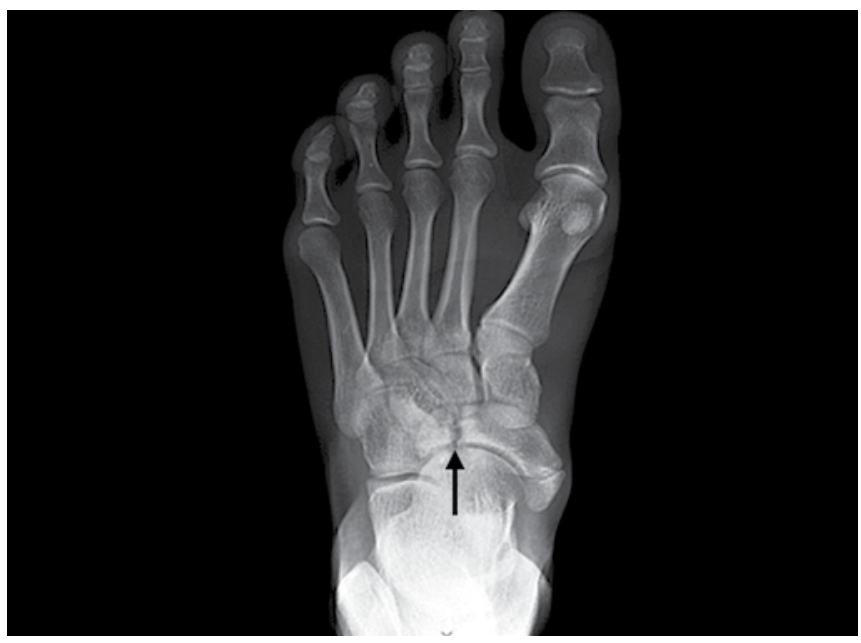

Fig. 1: Radiograph of the foot and ankle showing nonunion at the lateral aspect of the navicular bone with sclerosed and irregular margins

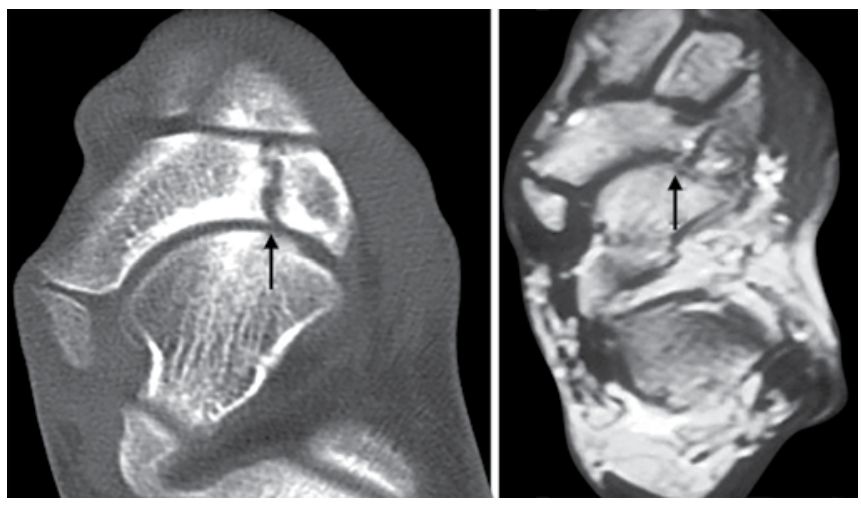

Fig. 2: Computed tomography and magnetic resonance imaging scan of the foot showing stress fracture nonunion 
Considering the diagnosis of nonunion with clear gap, we planned for cancellous screw fixation with iliac crest strut grafting for navicular stress fracture.

Through anterior approach, stress fracture ends, identified in the medial half of the navicular, were curetted and freshened. A gap of $3 \mathrm{~mm}$ (Fig. 3A) was found and was fitted with a $5 \mathrm{~mm}$ width of iliac crest strut graft (Fig. 3B). Fixation was done with a $4 \mathrm{~mm}$ partially threaded cancellous screw under the guidance of image intensifier. Below knee cast was applied. Patient was mobilized with nonweight bearing for 6 weeks followed by partial weight-bearing for the next 4 weeks. After 10 weeks, full weight-bearing was allowed.

Follow-up radiograph and CT scan (Fig. 4) were performed at 6 months to assess bony union. The scan findings correlated with patient's clinical cure. At the end of 6 months, she was allowed to jog and run at higher speeds. After 8 months, she was able to resume sports related activities.

\section{DISCUSSION}

Towne et al in the year $1970^{2}$ described stress fracture of the tarsal navicular for the first time. While there is some information available on delayed diagnosis in literature, information on its management, nonunions, and potential complications is not described and discussed well enough in literature, especially in young athletes. Biomechanically unsuited excessive stress on a foot, associated with sports activities, may cause such fractures. They occur in the sagittal plane, usually within the central third of the bone and start on the dorsal proximal articular border. ${ }^{3}$

Tarsal navicular stress fractures are often missed by physicians. $^{2}$ The average lag time between symptoms and diagnosis is between 4 and 7 months. If diagnosis is delayed, symptoms can begin to affect walking and daily activities. Initial physical findings are nonfocal, with vague pain radiating along the medial longitudinal arch or along the dorsum of the foot. Because of this vagueness, diagnosis is often missed. In later stages, the pain from a tarsal navicular stress fracture localizes along the dorsum of the navicular bone, the appropriately named $\mathrm{N}$ spot. $^{3}$

The location and unique impingement during foot strike of the navicular bone predispose it to well-localized stress and remodeling. ${ }^{4}$ During the foot strike, the navicular bone is impinged with maximum pressure between the proximal talus and the distal cuneiforms. Biomechanical analysis of navicular motion during stride reveals that most of this impingement force is focused at the central one-third of the navicular bone. ${ }^{5}$ This anatomic impingement is even more significant, since microangiographic studies in fresh cadavers have shown that the central one-third of the navicular is relatively avascular and the site of fracture appears to commonly occur in this area of poor vascularity. ${ }^{3}$

Plain radiographs are unreliable in diagnosing tarsal navicular stress fractures, with only 33\% sensitivity. ${ }^{7}$ Triple phase nuclear bone scans are more sensitive than plain radiographs in the detection of stress fractures early in the clinical course. ${ }^{3}$ A fine-slice CT scan of the talonavicular joint is required to diagnose navicular stress fracture. ${ }^{6}$ Magnetic resonance imaging is considered as the best imaging choice for studying stress fractures.

If they are diagnosed early, most of the incomplete tarsal navicular stress fractures with no displacement or angulation can be managed without surgery. The preferred regimen is 6 weeks of short leg non-weightbearing cast, followed by 4 to 6 weeks of transitional weight-bearing cast, later gradual return to full weightbearing with a semirigid shoe. ${ }^{8}$ Weight-bearing during conservative treatment, however, increases the incidence of nonunion and avascular necrosis. ${ }^{2}$ Surgery should be recommended as first line of treatment for patients with

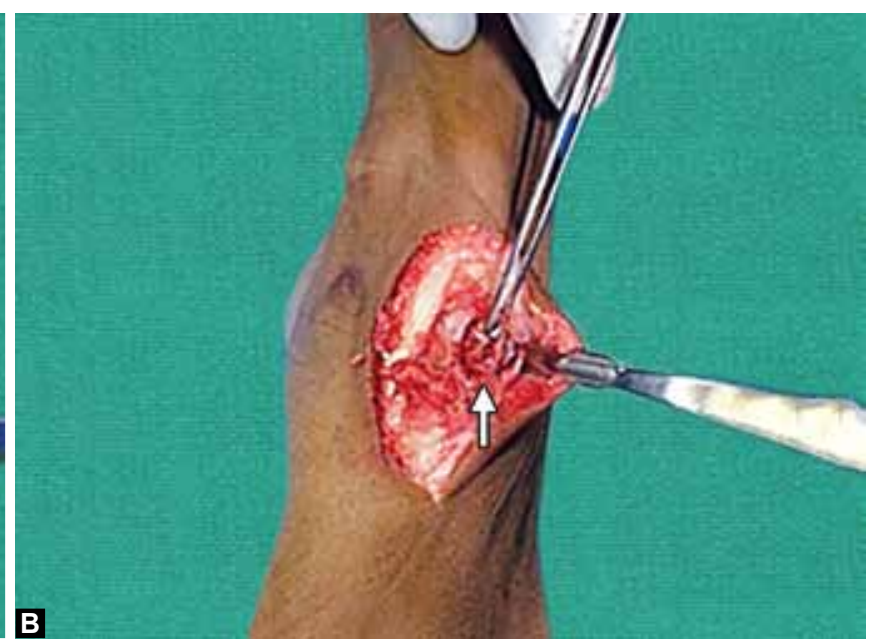

A

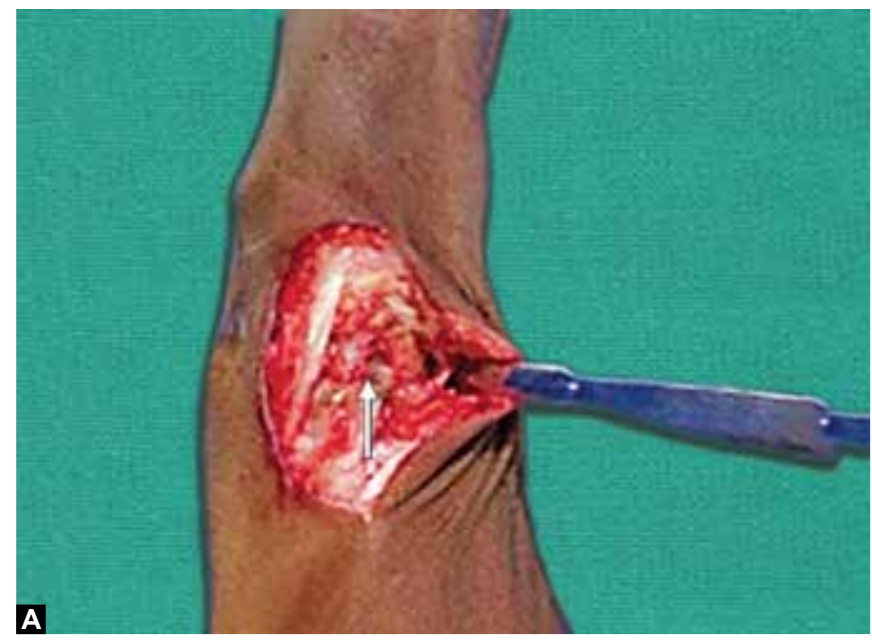

Figs 3A and B: (A) Intraoperative image showing stress fracture-gap after curettage and (B) Intraoperative image showing incorporation of iliac strut graft 


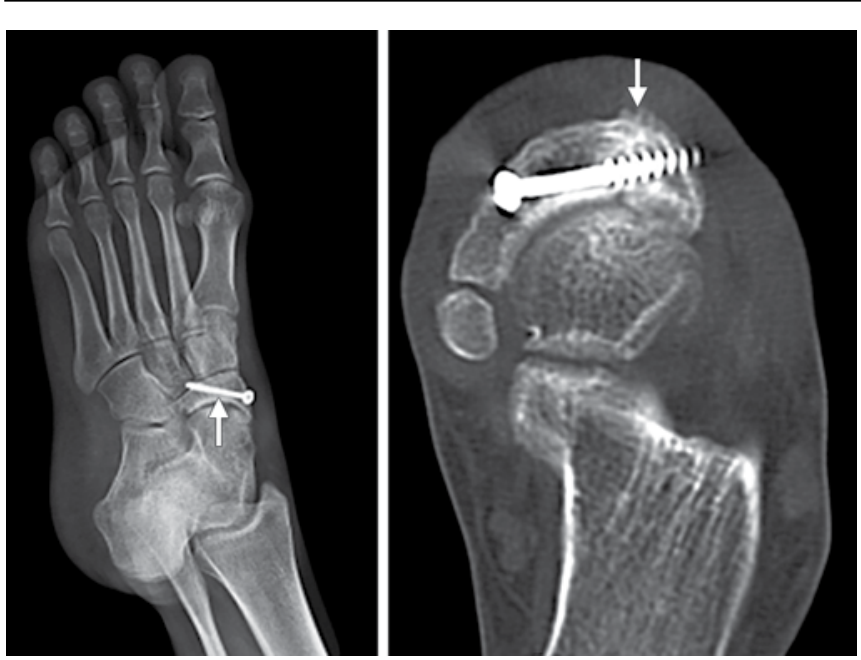

Fig. 4: Radiograph and computed tomography scan at 6 months follow-up showing complete bony union

displaced fractures or in cases with nonunion, and in noncompliant patients.

In one of the studies by Khan et al out of 86 navicular stress fractures, 80 fractures were conservatively managed, out of which 22 were treated with nonweight bearing cast for $\geq 6$ weeks, 13 with nonweight bearing cast for 2 to 5 weeks, 34 with limitation of activity for $\geq 6$ weeks, 6 with limitation of activity for 3 to 5 weeks and had success rates of $86,69,26$ and $50 \%$, respectively. In 5 cases who continued activities related to sports, the success rate was only $20 \%$.

In this study, only six out of 86 were primarily treated by surgery, three by internal fixation with screws ( 2 complete and 1 partial fractures) and the other three by excision of small fragments. Five ( $83 \%$ ) out of these six patients had good outcome, with an average of 3.8 months to return to sports. When surgery was used as a second-line treatment in 22 fractures ( 15 cases failed after limitation of activity with weight-bearing, 1 case of failed nonweight bearing cast immobilization, 3 cases of failed continued sports activity and in 3 cases with failed conservative treatment of less than 6 weeks), five were treated with excision of the small fragments, eight with internal fixation alone, six with only bone grafting and the rest three with bone grafting and internal fixation with an average success rate of $68 \%$ and average return to sports in 5.4 months. ${ }^{8}$

Even neglected (one- and half-year) stress fracture treated with iliac crest strut grafting and cancellous screw fixation yielded excellent outcome. Patients should subsequently undergo rehabilitation, including muscle strengthening, mobilization, and gradual resumption of activities.

Follow-up radiographic studies are not generally useful in showing cure because radiographic findings lag clinical healing and might never completely return to normal. ${ }^{9}$ But in our case complete radiological union was achieved at 6 months follow-up and confirmed by CT scan, correlating well with the clinical cure.

\section{SUMMARY}

Tarsal navicular stress fractures should also be considered in a young athlete with vague, ill-defined foot pain. Careful examination combined with specific radiologic studies (CT scan, MRI) can confirm the diagnosis. Most of them can be managed conservatively by strict nonweight bearing casting with good outcome.

Even if neglected, like in our case, satisfactory outcome can be achieved by open reduction and internal fixation with cancellous screw and iliac crest strut grafting followed by appropriate rehabilitation.

\section{REFERENCES}

1. Bennell KL, Brukner PD. Epidemiology and site specificity of stress fractures. Clin Sports Med 1997 Apr;16(2):179-196.

2. Towne LC, Blazina ME, Cozen LN. Fatigue fracture of the tarsal navicular. J Bone Joint Surg Am 1970 Mar;52(2):376-378.

3. Torg JS, Pavlov H, Cooley LH, Bryant MH, Arnoczky SP, Bergfeld J, Hunter LY. Stress fractures of the tarsal navicular. J Bone and Joint Surg 1982 Jun;64(5):700-712.

4. Khan KM, Brukner PD, Kearney C, Fuller PJ, Bradshaw CJ, Kiss ZS. Tarsal navicular stress fracture in athletes. Sports Med 1994 Jan;17(1):65-76.

5. van Langelaan EJ. A kinematical analysis of the tarsal joints. An X-ray photogrammetric study. Acta Orthop Scand Suppl 1983;204:1-269.

6. Alfred RH, Belhobek G, Bergfeld JA. Stress fractures of the tarsal navicular: a case report. Am J Sports Med 1992 NovDec;20(6):766-768.

7. O'Connor K, Quirk R, Fricker P, Maguire K. Stress fracture of the tarsal navicular bone treated by bone grafting and internal fixation. Three case studies and a literature review. Excel 1990;6:16-22.

8. Khan KM, Fuller PJ, Brukner PD, Kearney C, Burry HC. Outcome of conservative and surgical management of navicular stress fracture in athletes. Eighty-six cases proven with computerized tomography. Am J Sports Med 1992 NovDec;20(6): 657-666.

9. Kiss ZS, Khan KM, Fuller PJ. Stress fractures of the tarsal navicular bone: CT findings in 55 cases. AJR Am J Roentgenol 1993 Jan;160(1):111-115. 